\title{
INSTRUCTIONAL STRATEGIES TO REVITALISE THE INTEREST OF STUDENTS TOWARDS BASIC SCIENCES
}

\author{
H.S. Ganesha Bhatta*
}

\section{Teaching is not Mere Telling; It is that which Promotes Learning}

Teaching has an everlasting impact on the minds of students. Effective learning comes from strategically planned activities during the process of instruction. This could be done when we create environments in which students can actively participate in the process. Well tested innovations that focus on problem solving and creativity through planned activities in lectures, discussions and laboratories produce strong student learning.

Emphasis must be given to the process of thinking. In the words of His Excellency Dr. APJ Abdul Kalam, President of India, "Human mind is a unique gift. You can

\footnotetext{
* Professor of Education, MES Teachers College, Rajajinagar, Bangalore.
} 
enter into it only if you have curiosity and thinking. I suggest to all of you, thinking should become capital asset, no matter whatever ups and downs you come across in your life. Thinking is Progress" (Convocation Address $-21^{\text {st }}$ Convocation of Sri Sathya Sai Institute of Higher Learning). He has expressed his profound faith in empowerment of child, teacher, individual, team, woman and the leader. According to him "when the teacher is empowered with knowledge and experience good young human beings with value systems take shape."

\section{Journey of Excellence}

What is important in the classrooms of schools and colleges today is not the downpour of information (knowledge) to improve the quality of teaching. This is because, with Information Technology (IT) and access to Internet, students can 'down-load' information within no time. The teachers today have to know the art of using and applying the knowledge to create interest and arouse curiosity. The knowledge should be blend with skills to begin the journey of excellence. The teachers have to accept the skills development concept and prepare one's own strategy towards this. The 'skills' are essentially human, with a strong urge to learn, which builds self-confidence, self-esteem and enhance self-concept, through positive attitude which should result in the change of MIND-SET.

Learning refers to changes in behaviour that result from previous successful experiences in similar situations. Learning can occur in three dimensions - cognitive, affective and psychomotor. Teaching is a catalytic process which brings about desirable changes among learners.

The relation between teaching and learning, related to each domain is as shown below in the flow-chart: 


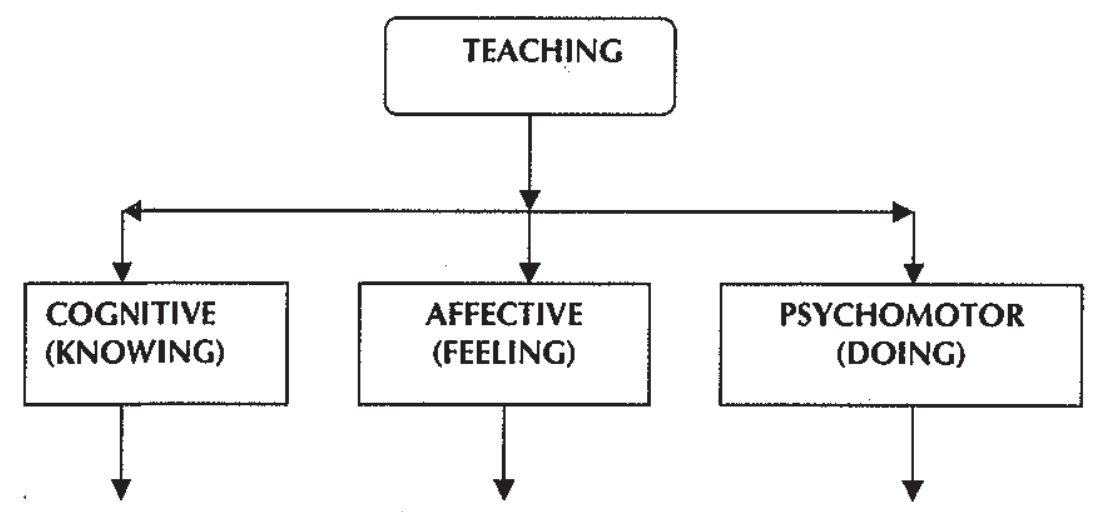

\begin{tabular}{|l|l|l|}
\hline Arriving at definitions & Interests & Assembling \\
\hline Deriving a formula & Attitudes & Manipulations \\
\hline $\begin{array}{l}\text { Processing of } \\
\text { Information for } \\
\text { Understanding to } \\
\text { Solve problems }\end{array}$ & Values & $\begin{array}{l}\text { Conducting } \\
\text { Experiments }\end{array}$ \\
\hline & $\begin{array}{l}\text { Disciplining the } \\
\text { mind }\end{array}$ & $\begin{array}{l}\text { Correcting } \\
\text { Apparatus }\end{array}$ \\
\hline & & Interpreting tables \\
\hline & & \\
& LEARNING & \\
\hline
\end{tabular}

Learning refers to managing and using past experience for acquiring knowledge through new experiences. The role of teacher in this context need not be overemphasized. Learning is the result of varied experiences. Teacher should be aware of the factors that promote learning, in order to be an effective communicator.

\section{Factors that Affect Learning}

- Participation of students

- Transfer of learning 
- Linking instructional events with actual tasks in jobs

- Learning outcomes

- Mode and the rate of learning

- Provision for Learning experiences

- Self-evaluation among students

- Repetitive practices

- Appealing to various senses in an integrated way

- Knowledge about the performance

- Difficulties experienced by the students in the process of learning

- Owning responsibility for learning

Thus to make the process of instruction effective, teacher should be able to do the following:

- Understand the terminal performance to be achieved by students

- Present the matter in a clear and well-organised manner

- Provide adequate 'learner friendly' learning materials and experiences

- Allow adequate time to mastery

- Accommodate to individual learning problems and learning styles.

- Use active methods of teaching.

\section{How could it be Done?}

Holding the attention of the students throughout the academic year is a challenge to any teacher. Striking a balance can be done by using a combination of different materials (see Appendix) and methods with varied permutations. Some of the methods that could be normally used in Higher Education are listed below: 


\section{Lecture:}

A lecture is a presentation of information in a direct logical manner - Student interaction is insignificant.

\section{Demonstration:}

A teacher performs experiments - Students observe

\section{Group Discussion:}

Theme-based exchange of ideas and opinions in a group.

\section{Seminar:}

Presentation of a paper on a given topic by the students followed by discussion and analysis.

\section{Panel Discussion:}

A group of students present their views on a selected theme followed by discussion.

\section{Brain Storming:}

It is a process of generating ideas in a short time without evaluation. The ideas are considered based on their merit.

Role-playing:

It is a simulated condition which deals with problems through action.

Case-study:

It describes a situation and ends with a problem or issue for the students to solve. Interactive Multimedia:

A class of computer-driven interactive communication systems which create, store, transmit and retrieve, textual, graphic and auditory networks of information.

In addition to the above methods, teachers can also make use of visits, field trips and the dramatization techniques for effective learner-teacher interaction.

\section{Tenets of Teaching}

- Accept that all students can learn

- Learning is a continuous and an active process

- Induce enthusiasm in the students to learn

- Teaching refers to guidance 
- Develop appropriate materials and methods to teach

- Give a sufficient time for them to learn

- Set standards for the performance of learners.

\section{Conclusion}

Learning styles of most of the students and teaching styles of most of the teachers are compatible in several dimensions. Many of the students are visual, sensing, inductive and active and some of them are global; most higher education is auditory, abstract, deductive, passive and sequential. These mismatches lead to poor student performance, professional frustration and a loss to society of many potentially talented individuals.

Although the diverse styles with which students learn are numerous, the inclusion of a relatively small number of techniques in an instructor repertoire should be sufficient to meet the needs of most of the students in any class.

The idea, however, is not to use all the techniques in every class, but rather to pick several that look feasible and try them; keep the ones that work; drop the others. In this way, a teaching style that is effective can be evolved with a potentially, dramatic effect on the quality of learning that subsequently occurs. 